\title{
Realtime Fingerprint based Voting System
}

\author{
Madhuri Namballa \\ Assistant professor(CSE) \\ GITAM (Deemed to be University) \\ India
}

\author{
${ }^{1}$ Mendu Vaishnavi \\ Computer Science and Engineering \\ GITAM (Deemed to be University) \\ India \\ ${ }^{2}$ Tejasree Kaka \\ Computer Science and Engineering \\ GITAM (Deemed to be University) \\ India
}

\author{
${ }^{3}$ Duvvuri Sai Suma \\ Computer Science and Engineering \\ GITAM (Deemed to be University) \\ India \\ ${ }^{4}$ K. Sriram \\ Computer science and engineering \\ GITAM (Deemed to be University) \\ India
}

\begin{abstract}
This report is based totally on "REALTIME FINGERPRINT BASED VOTING SYSTEM". The main intention of this proposal is to offer security and to overcome the limitations that are in the conventional balloting system. Initially, within the consumer registration procedure, the voter details, along with their fingerprint, are saved within the serial monitor. Here, the serial monitor acts as a database. The voter desires to area their finger at the module on the polling booth, thus allowing the acquisition of a finger impression from the voter, which serves as identification. Then the impression is passed on to the controlling unit for verification. The microcontroller fetches the statistics from the voter and compares it with the already present information stored at some stage in the registration of the voter. If the statistics fit with already existing statistics, then the voters are allowed to cast their votes. The voting mechanism is done manually through the use of pushbuttons. The welcome instruction and with the parties is displayed on the LCD. Whereas, the voter details and results are displayed on the screen.
\end{abstract}

Keywords: Arduino, Fingerprint, Microcontroller, Voting.

\section{INTRODUCTION}

"REALTIME FINGERPRINT BASED VOTING SYSTEM" is one of the voting techniques in which people who are majors with Indian citizenship can cast their vote. These days the voting machine has become an effective toll compared with traditional paper-based voting techniques. Thus, we decided to design a machine to overcome the already existing voting system. The main scheme of this project is to have more secure, no duplication of votes and declare the results as early as possible.

In this system, we use the Arduino board, which consists of a microcontroller, connected with the EEPROM microcontroller of the fingerprint module here the information is stored. Firstly, the voter has to give their impression to start the process while casting their vote and also for the enrolling process. In this voting system, fingerprint plays a significant role because it secures the voter's data and takes safety measures to avoid the duplications of votes while casting their vote.

\section{LITERATURE SURVEY}

1) Vishal Vilas Natu, "voting gadget" is completely on paperwork and electronics device. There is greater office work to keep records of the voter and the voter has to go to the poll container by using carrying voter id for authentication. Using machines, the voter casts their vote once authentication is accomplished by electing govt. The device includes a list of applicants and other details. More than one buttons are present in front of their specific call via setting the fingerprint, the voter can donate their vote to the candidate.

2) Khasawneh said in paper-primarily based elections, citizens solid their votes by truly setting their vote in sealed packing containers dispensed across the electoral system circuits around a given country. When the election length ends, all these packing containers are opened and the votes were counted manually within the presence of the certified officers. In this, the patron and the database, producing reports, sending method, there can be errors in counting of votes or a few messages to voters in the previous procedure. Cases electorate discover methods to vote extra than once automatically. Sometimes electorates are even manipulated to distort the effects of an election in favor of positive candidates.

3) Prasad, Halderman, Proposed in the International Journal for Research "Security Analysis of India's Electronic voting machines". The author said security is the heart of the E-voting system, he developed this for a security reason to overcome the duplications with a wide variety of security measures. 


\section{BLOCK DIAGRAM}

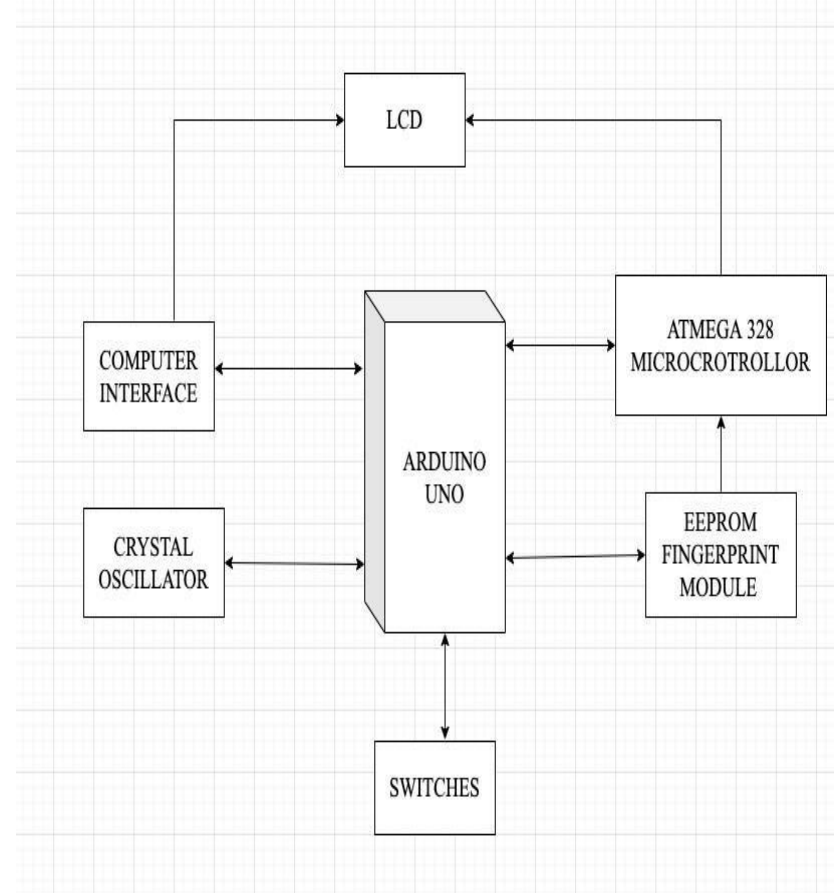

\section{Arduino UNO:}

The Arduino UNO connects all the essential parts. It consists of an Atmega328 microcontroller, which is one of the most used mega chips in the Arduino. It also consists of an onchip flash memory to which the code is uploaded. This board provides 14 digital input-output pins, out of which 6 are PWM pins (Pulse Width Modulation), and the other 6 pins are analog inputs.

\section{EEPROM Fingerprint Module:}

The fingerprint module is one of the most prominent devices of the project. We use this module to acquire the fingerprint of a voter. The module used in this paper is R303. This module captures a high-quality image, resulting in a better matching process. The comparison process is very efficient as we could check every ridge, whorl, and valley with the already existing fingerprint.

\section{Atmega328 Microcontroller:}

The Atmega328 is an 8-bit microcontroller. It comprises of flash memory along with read-write capabilities. To store the code, we use the EEPROM residing in the microcontroller. One of the main advantages of this microcontroller is, it optimizes the power use and provides high-performance speed.

\section{Crystal Oscillator:}

The crystal oscillator plays a principal role in the implementation of this project. It produces a frequency of $16 \mathrm{Mhz}$ to continue the process of execution. Using this, we can estimate the time of execution. As the frequency is $16 \mathrm{Mhz}$, the time taken to execute each line of the code would be $1 / 16$ microseconds.

\section{LCD}

We use the LCD (Liquid crystal display) to display details to the voters. The dimension of the LCD used is $16 \mathrm{X} 2$, which means it has 16 columns and 2 rows. We are using the LCD to display the access granted message to the voter, followed by the parties competing in the elections. After voting, the LCD displays the party to which the voter casts their vote.

\section{Computer Interface:}

The system is connected to the Arduino board to supply power. We also use it in the enrollment process. After every enrollment, the code residing in the computer will be sent to Arduino. It gives instructions to the voter as to when they should place or remove the finger.

\section{Switches:}

This paper uses manual switches, which can also be referred to as push buttons, to vote. Each party has a separate button through which a voter can cast their vote to a party of their choice.

\section{PROPOSED WORK}

\section{Algorithm of Fingerprint Based Voting System:} Step 1: Start

Step 2: Users can register by giving their fingerprints. We use a microcontroller to store them.

Step 3: Scan your finger

Step 4: If match found goto step 5 else return to step3

Step 5: user checks their details

Step 6: cast your vote

Step 7: Press push-button for a party from the party list Step 8: Vote counted

Step 9: Stop

\section{Fingerprint Identification and Matching:}

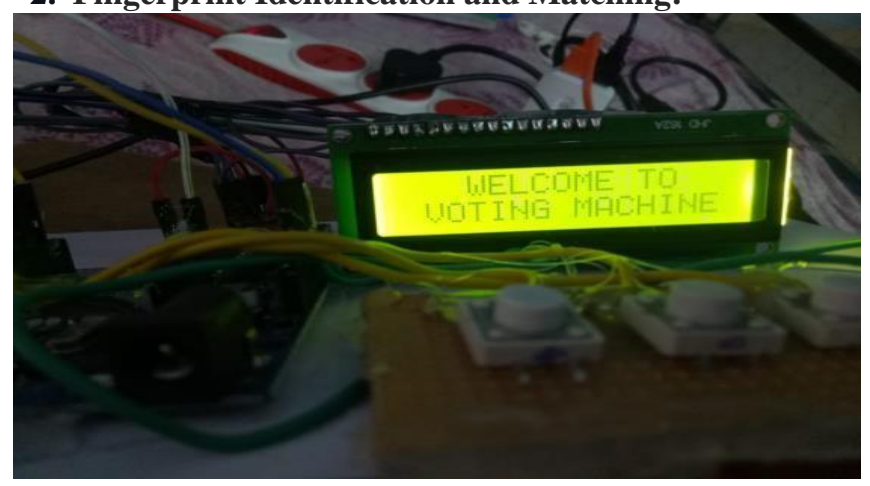

Fundamentally, we utilize advanced imaging innovation in securing, putting away, and dissecting the unique mark information.

\section{1) Acquiring Images:}

In the image identification process, the first step is to obtain an image as, without it, we cannot perform further steps. To acquire an image of a fingerprint, the person needs to place their finger on the sensor. Once the voter places their finger, 
on one end of the prism, the total internal reflection occurs through which we can capture the image using the image sensor and lens from another end of the prism. But the image extracted in this step is unprocessed.

The position and placement of the finger play a prominent role in the process of capturing an impression. For intensifying the total internal reflection and capture a fingerprint of good quality with the image sensor, we need to make sure that the finger is placed correctly on the module.

\section{2) Storing the images:}

The unprocessed image acquired in the previous step is now processed using image segmentation.

Image Segmentation: The captured images may contain some redundant data and noise along with required data, so we use image segmentation in which we divide the image into many segments called pixels to remove the irrelevant data. To ease the process of image analysis, we use image segmentation.

We use the normalization of an image to get even pixels. Once the pixels are uniform, it results in the formation of an image, and then to reduce or remove the noise present in it, we use the Gabor filter. The thresholding technique is implemented on the filtered image to change it into a binary image, then we compare threshold values and pixel values, if the value is higher than the threshold value then we set the pixel value to 1 else 0 . Next, to remove some pixels from the foreground, we implement the thinning process. Finally, all the segments form a single image.

\section{3) Analyzing the Image:}

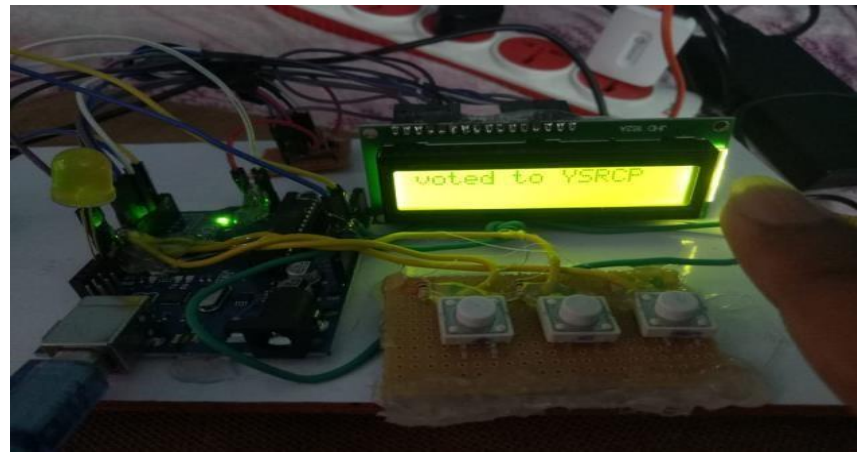

Finally, it shows to whom the user cast the vote.

Using image analysis, we can retrieve all related data from the image for further use. Mostly some electrical machines are used to collect the required data. According to this project, the electrical machine is a fingerprint module through which we capture the fingerprint. The retrieved data from the image can be compared with data stored in different storage devices for identification, authentication, etc.
RESULT

Firstly, the message welcome to the voting machine is

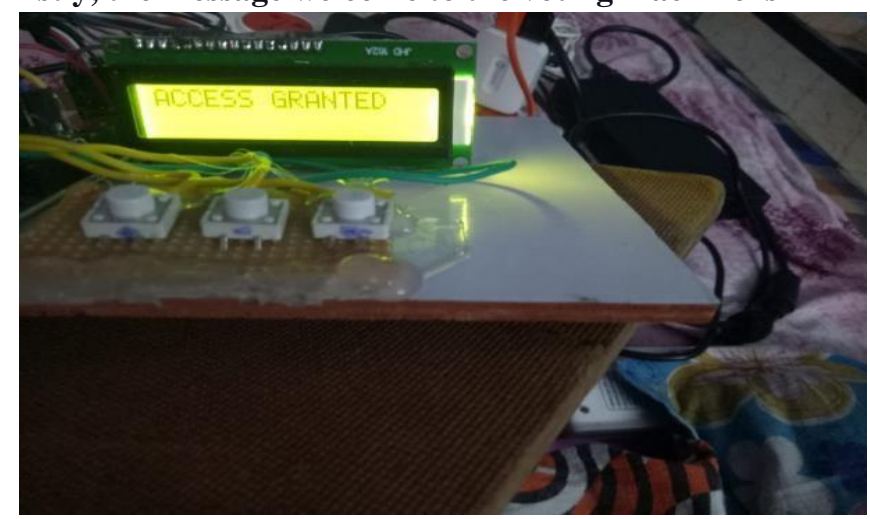

displayed on the LCD screen.

Once the

fingerprints are matched then the message ACCESS

GRANTED is displayed on the LCD screen.

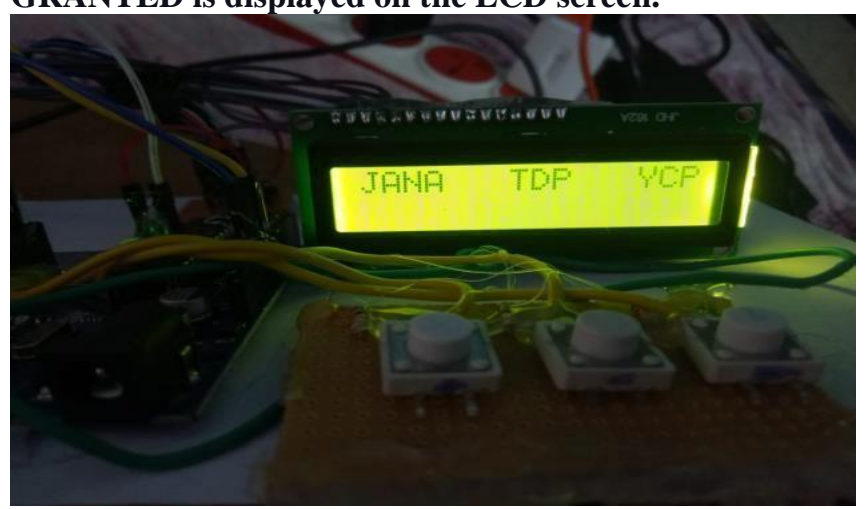

In the next step the voters can cast the vote by using the pushbuttons.

\section{CONCLUSION}

Through this project, we put forward an ideal electronic voting machine that uses a microcontroller to handle all the processes. This system is easy to use, convenient and economic in comparison with the conventional paperbased vote casting scheme. It may be used instead of the ballot system as additional security is assured in the proposed machine. The main advantage of using this system is that as fingerprints of everybody is specific and unique, the duplication of votes can be avoided.

\section{FUTURE SCOPE}

Further improvement of the prototype device could be done at the later development by using multiple fingerprint modules for every party so that it is more secure.

\section{REFERENCES}

[1] Khasawneh, M., Malkawi, M., \& Al-Jarrah, O., "A Biometric-Secure e-Voting System for Election Process," Proceeding of the 5th International Symposium on Mechatronics and its Applications (ISMA08), (2008), Amman, Jordan.

[2] Prasad, H. K., Halderman, A. J., \& Gonggrijp, R.,"Security Analysis of India's Electronic Voting Machines," International Journal For Research In Emerging Science And Technology, Volume-2, Issue-3, E-Issn:2349-7610, March-2015

[3] Schurmann, C.; IT Univ. of Copenhagen,

[4] Copenhagen, Denmark. -Electronic Elections: rust through Engineering \|, First international workshop Requirements Engineering for E-Voting Systems (RE-VOTE), 2009. 
[5] D. Ashok Kumar, T. Ummal Sariba Begum A Novel design of Electronic Voting System Using Fingerprint International Journal of Innovative Technology \& Creative Engineering (Issn: 2045-8711) Vol.1 No.1 January 2011

[6] Kashif Hussain Memon, Dileep Kumar and Syed Muhammad Usman, Next Generation A Secure E-Voting System Based On Biometric Fingerprint Method 2011 International Conference On Information And Intelligent $\quad$ Computing IPCSIT Vol.18 (2011). 